\title{
Clinical utility of platinum chromium bare-metal stents in coronary heart disease
}

This article was published in the following Dove Press journal:

Medical Devices: Evidence and Research

27 August 2015

Number of times this article has been viewed

Claudia Jorge'

Christophe Dubois ${ }^{1,2}$

'Department of Cardiovascular Medicine, University Hospitals Leuven,

${ }^{2}$ Department of Cardiovascular

Sciences, Katholieke Universiteit

Leuven, Leuven, Belgium
Correspondence: Christophe Dubois Department of Cardiovascular

Medicine, University Hospitals Leuven, Herestraat 49, B 3000 Leuven, Belgium Tel $+32 \quad 16344235$

Fax $+32 \quad 16344240$

Email christophe.dubois@uzleuven.be

\begin{abstract}
Coronary stents represent a key development for the treatment of obstructive coronary artery disease since the introduction of percutaneous coronary intervention. While drug-eluting stents gained wide acceptance in contemporary percutaneous coronary intervention practice, further developments in bare-metal stents remain crucial for patients who are not candidates for drug-eluting stents, or to improve metallic platforms for drug elution. Initially, stent platforms used biologically inert stainless steel, restricting stent performance due to limitations in flexibility and strut thickness. Later, cobalt chromium stent alloys outperformed steel as the material of choice for stents, allowing latest generation stents to be designed with significantly thinner struts, while maintaining corrosion resistance and radial strength. Most recently, the introduction of the platinum chromium alloy refined stent architecture with thin struts, high radial strength, conformability, and improved radiopacity. This review will provide an overview of the novel platinum chromium bare-metal stent platforms available for coronary intervention. Mechanical properties, clinical utility, and device limitations will be summarized and put into perspective.
\end{abstract}

Keywords: bare metal stent, coronary stent alloys, coronary artery disease

\section{Introduction}

Coronary artery disease (CAD) is the leading cause of death in the world and is responsible for 7.4 million deaths in 2012. ${ }^{1}$ Major advances in treatment and technology have led to a reduction in age-related cardiovascular deaths over the past 25-30 years. ${ }^{2}$ Paradoxically, however, the prevalence of CAD is expected to further increase as a result of the continuously growing epidemic of obesity and its consequences, including hypertension, dyslipidemia, and diabetes. ${ }^{2}$

The introduction of percutaneous coronary catheter interventions has revolutionized the field of coronary revascularization, and key developments in percutaneous coronary intervention (PCI) have significantly contributed to improve outcomes in patients with CAD: coronary bare-metal stents (BMSs) provided an answer to acute vessel closure, caused by dissection or elastic recoil after balloon angioplasty. ${ }^{3}$ While BMS prevented late lumen narrowing owing to vascular remodeling, they simultaneously triggered neointimal proliferation, ultimately leading to in-stent restenosis. ${ }^{3}$ Drug-eluting stents (DESs) virtually eliminated restenosis, providing controlled antiproliferative drug release from BMS carriers. ${ }^{4}$ While the latest revolution in interventional cardiology introduced fully resorbable scaffolds with a promise of vessel restoration, lumen enlargement, and regained vasomotion, ${ }^{5}$ versatile engineering of permanent metallic implants represents a unique opportunity to improve stent delivery, conformability and radial strength, both for BMS and DES. 


\section{Position of bare-metal coronary stents in current interventional practice}

BMSs are currently used in $15 \%-20 \%$ of coronary stent implantations, ${ }^{6}$ despite being significantly less effective than DES at inhibiting neointimal proliferation in response to strut-associated vascular injury and inflammation. ${ }^{7}$ Continued interest in BMS and further developments in the field have three clear explanations.

First, the initial enthusiasm of neointimal growth control with DES was tempered by reports of incomplete endothelialization and late-stent thrombosis. ${ }^{8}$ Animal studies demonstrated incomplete healing with DES at 180 days, whereas BMS uniformly showed complete endothelialization at 28 days. ${ }^{9}$ Despite a somewhat longer endothelialization process in humans, ${ }^{10} \mathrm{BMSs}$ in stable CAD require therefore short duration (1 month) dual antiplatelet treatment (DAPT), while guidelines continue recommending prolonged ( $>6$ months) DAPT with DES, even with latest-generation products. ${ }^{11}$ Consequently, concerns about compliance to prolonged DAPT and bleeding risk, especially in an aging population, represent the primary reason to use BMS in a subgroup of patients with CAD. ${ }^{12}$ Similarly, planned noncardiac surgery within 12 months, need for anticoagulation, and finally cost may also play a role in the choice of BMS over DES. ${ }^{12,13}$

Second, the benefit of DES in reducing neointimal hyperplasia and restenosis seems to be most pronounced in patients with diffuse CAD, small vessels, and diabetics, whereas restenosis rates with BMS in nondiabetic patients with large vessels $(\geq 3 \mathrm{~mm}$ ) and discrete short stenoses $(\leq 15 \mathrm{~mm})$ are similar to DES. ${ }^{13-15}$ Moreover, the benefit of DES seems to be mostly limited to the prevention of restenosis and reintervention, while patients treated with BMS or DES have similar rates of death and acute myocardial infarction (MI). ${ }^{16}$

Finally, latest generation (bare)-metallic stents are a formal part of contemporary DES technology. Indeed, in addition to developments in antiproliferative drug and polymer coating for DES, key improvements in design and metal alloy composition of the BMS platform have been shown to affect acute stent performance and clinical outcome. ${ }^{17-19}$

\section{Platinum chromium bare-metal stents}

Acute clinical performance of BMS is determined by a complex interplay of metal alloy and stent design. In an ideal setting, a coronary stent should be highly deliverable, owing to a thin strut and low-profile flexible design, while providing appropriate radial strength, near-absent recoil, and high radiopacity. ${ }^{17}$

\section{The platinum chromium alloy}

Stainless steel (SS) (316L) was for many years the preferred alloy for coronary stents, combining excellent biocompatibility with adequate mechanical behavior, but suboptimal corrosion resistance. ${ }^{20-22}$ Further reduction of SS strut thickness to $130-140 \mu \mathrm{m}$ occurred at the expense of stent visibility, while improving stent trackability, flexibility, and deliverability. These design changes did not affect stent recoil and radial strength, and ultimately lead to reduced restenosis rates..$^{20}$ Loss of stent visibility was initially compensated by the introduction of gold coatings and highly radiopaque gold markers on SS stents. However, overall poor clinical performance and higher incidence of in-stent restenosis with these coatings, together with the relatively moderate yield strength of 316L SS, created the need for superior strength metal alloys. ${ }^{18,23,24}$

The introduction of a significant amount of cobalt and chromium in stent alloys (CoCr) allowed to significantly reduce strut thickness $(80-90 \mu \mathrm{m})$, while simultaneously modestly improving radiopacity (eg, density of $8.0 \mathrm{~g} / \mathrm{cm}^{3}$ for $316 \mathrm{~L}$ SS vs $9.1 \mathrm{~g} / \mathrm{cm}^{3}$ for the CoCr L605 Vision stent [Abbott Vascular, Santa Clara, CA, USA] and $8.4 \mathrm{~g} / \mathrm{cm}^{3}$ MP35N Driver stent [Medtronic, Minneapolis, MN, USA]). Reduced strut thickness with $\mathrm{CoCr}$ equally favorably affected elastic characteristics (flexibility/deliverability/ conformability) of stents, however, at the expense of more pronounced acute recoil as compared with $316 \mathrm{~L} \mathrm{SS}$ alternatives. ${ }^{18,23}$

Different from cobalt, platinum $(\mathrm{Pt})$ represents an attractive metal compound for stent alloys, owing to its superior strength, corrosion resistance, chemical stability, and biocompatibility. In combination with $\mathrm{Cr}$, Pt-containing stent alloys were specifically created and tested for coronary applications. ${ }^{18}$ Of the different alloy compositions tested, those using a fraction of $33 \% \mathrm{Pt}$ seemed to offer the best equilibrium between processability, strength, stability, and radiopacity. ${ }^{17}$ The improved strength of PtCr (480 MPa) compared to SS $(275 \mathrm{MPa})$ allowed a further reduction in strut thickness compromising neither radial strength, mechanical properties, nor radiopacity (Pt density of $9.9 \mathrm{~g} / \mathrm{cm}^{3}$ ) (Figure 1). ${ }^{17}$ Available PtCr stent platforms consist of $\mathrm{Pt}(33 \%), \mathrm{Cr}(18 \%)$, iron (37\%), nickel (9\%), molybdenum (3\%), and a trace of manganese, thereby reducing iron and nickel content when 


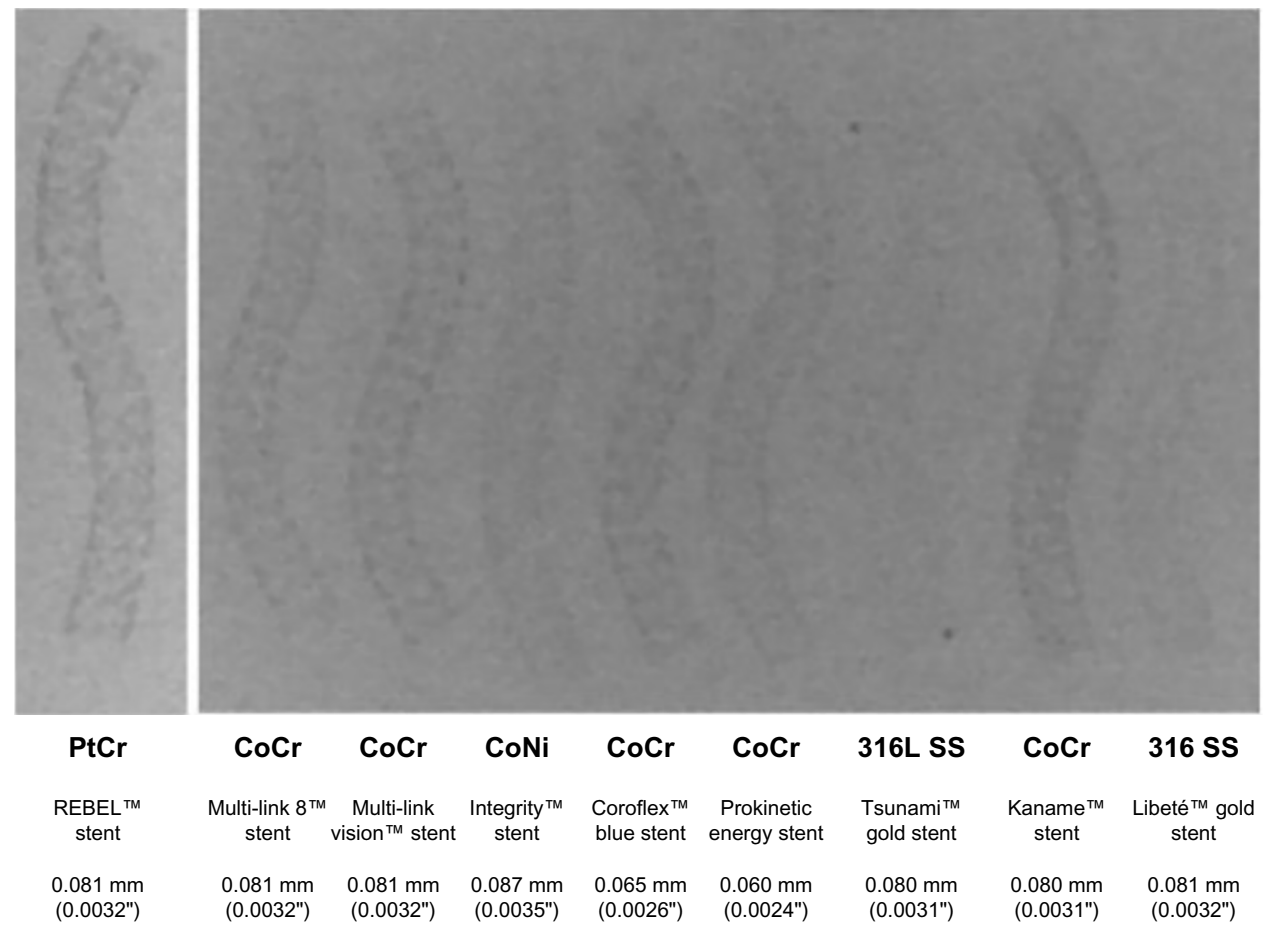

Figure I Visibility bench test comparison of distinct stent alloys.

Notes: Radiopacity of distinct stents with variable alloy composition is shown. The lower row indicates stent strut thickness (in mm and inch).

Abbreviations: PtCr, platinum chromium; CoCr, cobalt chromium; CoNi, colbalt nickel; SS, stainless steel.

compared to $316 \mathrm{~L} \mathrm{SS}{ }^{23}$ Details of stent processing have been described elsewhere. ${ }^{17,23,25}$

Biovascular compatibility of the $\mathrm{PtCr}$ alloy has been extensively assessed in a nondiseased swine model: 30 days, 90 days, and 180 days after implantation of $\mathrm{PtCr}, 316 \mathrm{~L} \mathrm{SS}$, and L605 CoCr BMS all three stent types showed indistinguishable histological findings and a similar clinical safety profile. $^{17}$

\section{Clinical implications of stent alloy modifications}

Thin-strut stents have been shown to improve stent crossing profile, contributing to superior trackability, a lower risk of occlusion of side branches, and related periprocedural MI. ${ }^{17}$ Thinner stent struts equally favorably impact on in-stent restenosis and thrombosis, likely due to reduced vascular injury ${ }^{17,19}$ and early and complete strut endothelialization. ${ }^{26}$

High radiopacity inherently improves procedural precision and safety by enhancing immediate stent visibility, a feature that is particularly valuable during complex PCI. Clinical scenarios clearly benefiting from improved stent radiopacity are fluoroscopy in extreme caudal projections, in obese patients, or when differentiating severe calcifications from stent edges. Likewise, proper stent imaging is fundamental when precise stent positioning determines the completeness and degree of stent overlap in long lesions in order to avoid geographical miss or long double-layered stent segments, respectively. Inappropriate stent overlap may indeed lead to target vessel failures, likely related to uncovered areas or excessive local drug-delivery and inflammation. Finally, appropriate visualization of stent edges facilitates precise high pressure noncompliant balloon postdilatation avoiding unintentional balloon damage beyond stent margins. ${ }^{17}$

Radial strength is a quantitative measure of stent scaffolding strength, and its resistance to extrinsic compression, maintaining vessel patency. This feature is of particular importance during PCI of aorto-ostial or highly fibrocalcific lesions. ${ }^{17}$

Low recoil, the ability of a stent to maintain its initial expansion diameter, is known to be associated with reduced risk of malapposition and late-stent thrombosis and restenosis. ${ }^{17}$

Finally, conformability is defined as the ability of a stent to adapt and support a tortous vascular anatomy without inducing vessel straightening. It may be one of the main predictors to avoid stent-induced injury and stent-edge dissections in complex vessel anatomies. Stent rigidity, the opposite of conformability, restricts the adaptive capability of stents in tortuous anatomies, potentially inducing a hinge effect and putting the patient at increased risk for restenosis. ${ }^{23}$ 


\section{Available platinum chromium stent designs}

The Element stent concept for DES and BMS

Coronary stents using the improved mechanical properties and radiopacity of the Pt-enhanced alloy were initially launched as the revolutionary Element (Boston Scientific, Natik, MA, USA) BMS platform for everolimus or paclitaxel elution (Promus Element and Taxus Element series, respectively).

The Element portfolio includes stent models with lengths and diameters ranging from $8 \mathrm{~mm}$ to $38 \mathrm{~mm}$ and from $2.25 \mathrm{~mm}$ to $4.0 \mathrm{~mm}$, respectively. Strut thickness of $81 \mu \mathrm{m}$, and a unique design of interconnected serpentine segments contribute to an excellent flexibility, deliverability, and conformability. ${ }^{25}$ Improved stent behavior is further enhanced by a limited number of connectors $(n=2)$ between segments, while connectors arranged in a kind of double helix configuration facilitate independent stent segment motion, while balancing forces in the stent (Figure 2). A particular design feature of the Element platform is the nested orientation of stent segment peaks, hereby avoiding strut-to-strut contact during stent tracking in tortuous anatomies, or during deployment in a bend. Finally, wider segment peaks and shorter segment lengths redistribute expansion strain in the longitudinal direction, hereby increasing radial strength, while simultaneously improving conformability. 23,25

In contrast with most other latest generation stents, often available in two models mounted on a wider range of balloon sizes, the Element stent platform was developed in four sizes to accommodate for an optimal surface-to-artery ratio(Figure 3). ${ }^{23,25}$ Such tailored design reduces the risk of plaque prolapse, by

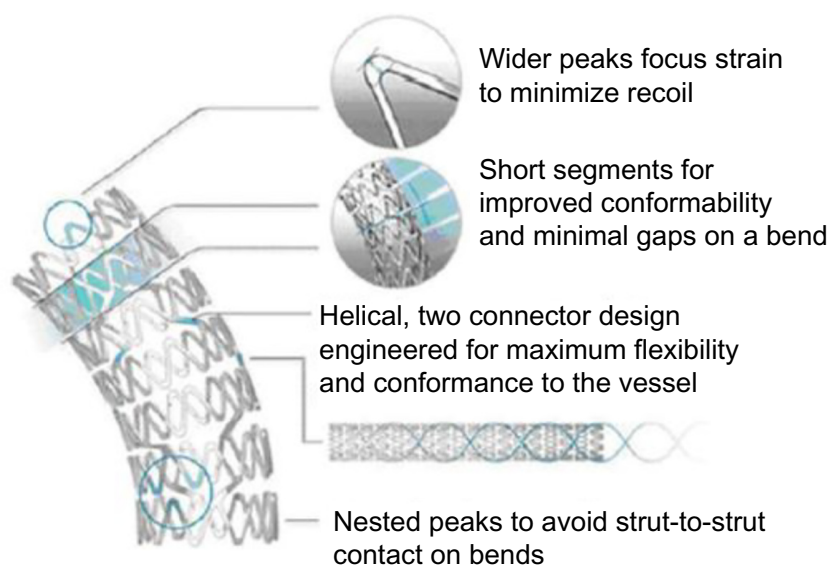

Figure 2 Design structure of the element PtCr stent platform.

Note: Reproduced with permission from Bennett J, Dubois C. A novel platinum chromium everolimus-eluting stent for the treatment of coronary artery disease. Biologics. 2013;7(1):149-159.25

Abbreviation: $\mathrm{PtCr}$, platinum and chromium. allowing more uniform scaffolding and contact with the vessel wall, hereby insuring a uniform drug release. The smaller $2.25 \mathrm{~mm}$ model stent has even a more individualized design with shorter (and thus more) segments per stent as compared with the larger diameter models as well as a lower system profile, optimizing the conformability and deliverability in small and often more tortuous vessels. ${ }^{23}$

Finally, stent performance in Element was optimized by implementation of a tailored stent delivery system, similar to the Apex balloon catheter (Boston Scientific), using a bisegment inner lumen technology to offer maximal distal shaft and balloon flexibility as well as proximal shaft pushability. ${ }^{23,25}$

The Element platform was consequently released as the Omega BMS (Boston Scientific), with identical mechanical properties without drug elution. These stent characteristics have been shown to translate into superior performance as compared with competitive BMS designs both in terms of conformability and recoil. ${ }^{23}$ The Omega portfolio offers BMS ranging in diameter from $2.25 \mathrm{~mm}$ to $4.50 \mathrm{~mm}$ and lengths of $8 \mathrm{~mm}$ to $32 \mathrm{~mm}$.

\section{Further refinements: Promus Premier and Rebel} The last generation PtCr platform for the Rebel BMS (Boston Scientific) and Promus Premier DES (Boston Scientific) is based on the Omega/Element stent. It introduces additional connectors within the proximal end of the stent to increase axial strength and resistance to stent deformation. Moreover, it uses an improved delivery system for increased resistance to compression while maintaining flexibility and deliverability. ${ }^{27}$ The customized stent architecture consists of two additional connectors between the first and second and between the second and third proximal segment for the $2.50-3.5 \mathrm{~mm}$ platforms for Rebel and Premier and three additional connectors for the 4.00-4.50 $\mathrm{mm}$ versions, enhancing in this way the axial strength (Figure 3 ). The length of each segment has been shortened at the expense of an increasing number of stent segments, to improve conformability, and to minimize gaps on a bend. The segment peaks were also widened to focus radial strength and minimize stent recoil.

Improvements in the mechanical characteristics of the stent delivery system for the Rebel BMS intend to reduce frictional force and enable precise stent delivery in challenging lesions. The catheter shaft uses a ZGlide coating, identical to the one used in the Emerge balloon (Boston Scientific). This hydrophilic coating is applied on the catheter between the wire port and the proximal balloon and increases lubricity as compared with the bioslide coating (Boston Scientific) on the Omega stent. The inner lumen catheter has a bisegment 

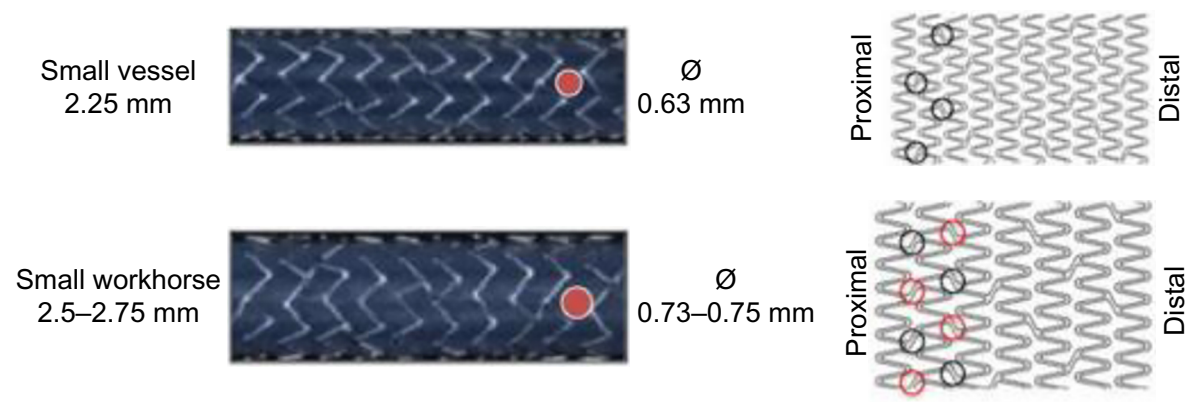

Workhorse $3.0-3.5 \mathrm{~mm}$
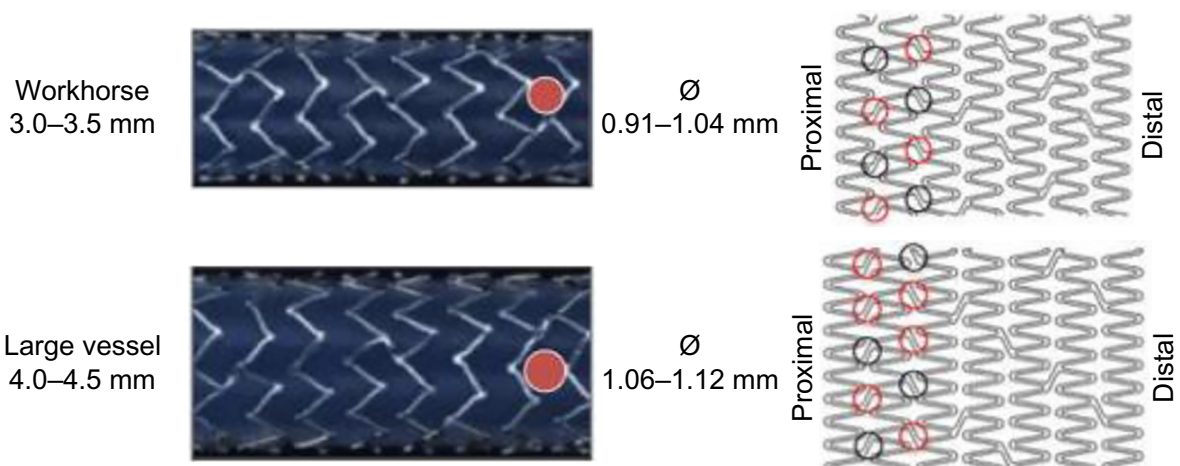

$\stackrel{\varnothing}{1.06-1.12 \mathrm{~mm}}$

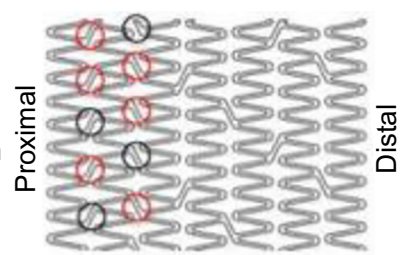

Figure $3 \mathrm{PtCr}$ stent models according to vessel size.

Notes: Four separate stent models were developed to optimize the surface-to-artery ratio over the range of coronary vessel diameters and provide more uniform scaffolding (small vessel, small workhorse, workhorse, and large vessel). In the left image panels, circular cell diameter (red closed circles) is shown to increase with larger models, providing easy side-branch access. The right image panels represent a graphic drawing of each available size model, showing the adapted design and added connectors at the proximal stent end in the Rebel/Promus Premier version. The red open circles highlight the additional connectors to increase longitudinal robustness. In these improved designs, workhorse stent models have eight connectors proximally, and large vessel models I0. More distal stent segments are unchanged with two connectors between stent segments.

customized design, with a pushable proximal segment and a flexible distal segment. The proximal hypotube is polytetrafluoroethylene coated for improved stent deliverability. Finally, the stent platform is mounted on a dual-layer pebax balloon (Boston Scientific), providing an optimal compliance with minimal balloon growth, in order to avoid stent overexpansion while maintaining appropriate stent apposition.

\section{Efficacy studies with platinum chromium stents}

Efficacy of the $\mathrm{PtCr}$ stent platform has been extensively tested for the everolimus-eluting version in randomized comparisons to $\mathrm{CoCr}$ stents eluting everolimus (PLATINUM) ${ }^{28}$ or zotarolimus (HOST-ASSURE) ${ }^{29}$ but detailed analysis of these results is beyond the scope of this review. For the PtCr BMS, the OMEGA Clinical Trial evaluated the safety and efficacy of the Omega stent in a prospective, single-arm fashion, comparing results to a prespecified performance goal. ${ }^{27} \mathrm{~A}$ total of 328 patients with de novo CAD in vessels of $2.5-4.5 \mathrm{~mm}$ in diameter were enrolled. The primary endpoint at 9 months was a composite of target lesion failure defined as any ischemiadriven target lesion revascularization (TLR), MI related to the target vessel or cardiac death. The Omega stent was superior to a prespecified performance goal based on prior generation BMS (target lesion failure $11.5 \%$ vs $21.2 \%, P<0.0001$ ). Cardiac death at 9 months occurred in $1.2 \%$ of patients, MI in $3.7 \%$, TLR in $7.4 \%$ and definite or probable stent thrombosis was as low as $0.6 \%$. While clinical restenosis leading to TLR was $7.4 \%$ at 9 months with Omega, angiographic binary restenosis (diameter stenosis $>50 \%$ ) was reported in $8.6 \%$ at 9 months and $9.9 \%$ at 1 year, thus at the lower end of the restenosis ranges commonly reported with BMS $(5 \%-35 \%){ }^{27}$ These rates are in line with those observed in the Driver registry (Driver stent restenosis $8.1 \%$ at 9 months), ${ }^{30} \mathrm{DaVinci}$ Registry (Multilink Vision 9.7\% at 9 months), ${ }^{31}$ and the bare metal arm of the Endeavor II randomized trial (Driver stent $14.1 \%$ at 12 months). ${ }^{32}$ In these trials, patients receiving a Driver stent had a larger vessel diameter and a shorter lesion length. In contrast, patients treated with Omega had the most complex lesion subset, with an average vessel diameter of $2.77 \mathrm{~mm}$ and lesion length of $12.49 \mathrm{~mm}$.

\section{Safety and tolerability of platinum chromium bare-metal stents}

The biocompatibility of the Pt alloy has been assessed in accordance with the usual battery of ISO 10993-1 tests and in 
a variety of porcine implant studies, as previously mentioned. However, from a vascular biomaterials perspective, endothelialization studies provide a better insight into cellular response to the surface characteristics. The importance of surface endothelialization has been well demonstrated for coronary stents, with poor endothelialization being associated with increased risk of thrombus formation and increased proliferation of smooth muscle cells. ${ }^{10}$ Endothelial cell assays showed comparable results for PtCr to $316 \mathrm{~L}-\mathrm{SS}$, one of the best materials in terms of supporting endothelial cell growth and migration. While this cell assay is of relatively short duration (14 days) it does address the most critical stage after implantation, when rapid endothelial cell coverage is desired. ${ }^{18}$ In addition, the presence of Pt would not be expected to impair endothelialization, as histological investigations on Pt embolism coils have shown endothelialization as early as 2 weeks after aneurysm treatment. ${ }^{33}$

The surface thrombogenicity and vascular healing process induced by the bare Element $\mathrm{PtCr}$ stent were also compared to the durable second-generation polymer coating polyvinylidene fluoride-co-hexafluoropropene used in the XienceV (Abbott Vascular) and Promus (Boston Scientific) everolimus-eluting stents. PtCr surfaces in contact with blood seem to be more biocompatible compared with polyvinylidene fluoride-co-hexafluoropropene-coated surfaces, since the latter tend to induce more thrombus, and subsequently, more neointima as well as a more delayed endothelialization. ${ }^{34}$ This last finding is equally supported by autopsy studies, suggesting that the permanent presence of these polymers may elicit chronic arterial inflammation, resulting in delayed healing and late thrombotic events. ${ }^{35,36}$ However, large comparative studies with DES with durable vs bioresorbable polymers failed to convincingly show a clinical benefit for DES with bioresorbable coatings. ${ }^{37,38}$

Finally, low rates of definitive stent thrombosis were reported with the PtCr Omega stent in the SCAAR registry, including 174,703 BMS and DES implanted since 2007 to October 2013 (Figure 4). ${ }^{39}$

Besides biovascular compatibility, the improved radiopacity/visibility of the $\mathrm{PtCr}$ platform may have led to improved procedural technical outcome at the lesion level, hence reducing the risk for stent thrombosis. ${ }^{40}$

\section{Longitudinal stent deformation}

Longitudinal stent deformation (LSD) has been recently recognized as a complication of coronary stent deployment, resulting from the elongation, shortening, or distortion of a stent in the longitudinal axis as a consequence of inadvertent device manipulation, and resulting in the need for additional measures, including repeat dilatation of the stent, deployment of another stent, and/or surgical intervention. ${ }^{41-43}$ This complication is expected to be rare, with an incidence estimated at $0.1 \%-1 \%$, although the first dedicated study identified LSD in $1.3 \%$ of the procedures. ${ }^{41,44}$ Mechanisms contributing

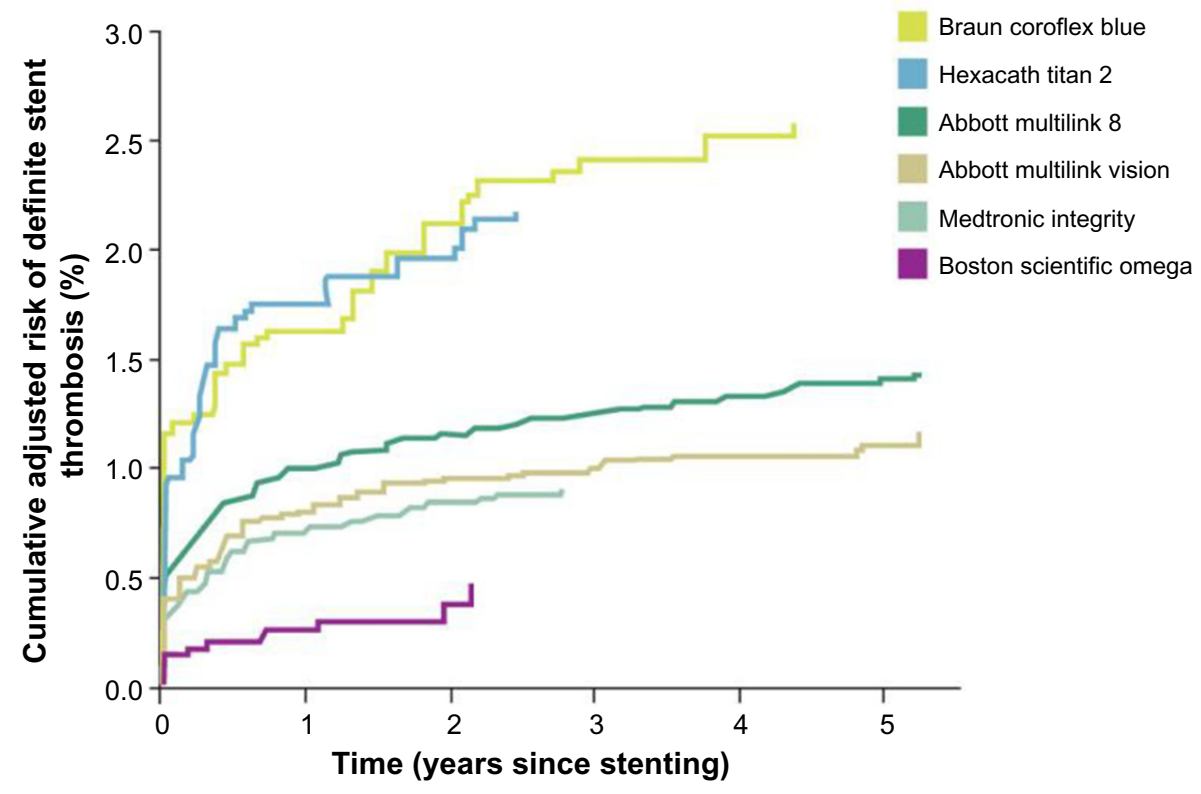

Figure 4 SCAAR stent thrombosis rates with various bare-metal stents.

Notes: The graph presents cumulative adjusted risk of definitive stent thrombosis with frequently used bare-metal stents in Sweden between 2007 and 2013 . Coroflex Blue, Multilink Vision, and Multilink 8 use a cobalt chromium alloy (CoCr); Titan: titanium stent with nitric oxide coating; Integrity uses cobalt nickel alloy (CoNi); Omega uses the platinum chromium alloy (PtCr). Modified with permission from SCAAR. Swedish Coronary Angiography and Angioplasty Registry. 20I5. Available from: http://www.ucr. uu.se/swedeheart/index.php/forskning-scaar/in-english/stent-reports. Accessed April I, 20I5. ${ }^{39}$ 
to this complication are not completely clear. In almost all cases reporting LSD, a direct force was applied at the level of the proximal stent segment, by compression by the guide catheter or guide extension, or when attempting to cross the freshly implanted stent with a secondary device (intravascular ultrasound catheters, additional undeployed stent, distal protection device and postdilatation balloon). ${ }^{44,45}$ Immediate outcome was usually uneventful, but correction of LSD often required considerable time and effort due to difficult crossing, while failure to reexpand the deformed stent may put the patient at risk for stent thrombosis. ${ }^{44}$

Significant differences in longitudinal strength between available stent platforms have been identified in recent engineering analyses as potential contributors to LSD. ${ }^{46,47}$ While LSD has been reported with at least eight stent designs, it appears to occur more frequently with the PtCr Element stent platform. A retrospective review of the FDA MAUDE database for device malfunctions reported LSD with the Element platform in 2010-2011 in 45 of the 57 (79\%) cases with stent deformation. ${ }^{43}$ Moreover, a recent retrospective and observational study of 450 consecutive procedures suggested that LSD is specific to the platform used $(3.1 \%$ with the Promus Element stent vs $<1 \%$ with the Biomatrix [Biosensors Europe, Morges, Switzerland), Resolute Integrity (Medtronic, Minneapolis, MN, USA] and XienceV [Abbott Vascular, Santa Clara, CA, USA] platforms). ${ }^{44}$ In contrast, a systematic independent analysis, specifically directed toward LSD in 2403 stents implanted in the PERSEUS and PLATINUM trials, did not identify cases with severe stent distortion among three different stent platforms with variable design, alloy composition (CoCr, PtCr, and 316L SS), and strut thickness (81-132 $\mu \mathrm{m})$. However, only $21 \%$ of all lesions treated in these trials were classified as ACC/AHA type C. ${ }^{48}$ Occurrence of LSD may, therefore, have been underestimated in this analysis, since lesions typically favoring stent distortion, such as chronic total occlusions, heavily calcified and tortuous vessels, and ostial lesions were excluded in these trials. ${ }^{45,48}$ Finally, in the most recent PE-prove trial, the occurrence of two cases of LSD out of 1,679 PtCr stents implanted in this study, highlights the low frequency of this procedural complication. These two cases, which were detected by angiography during the index procedure, represent classic examples of stent deformation resulting from interaction between an ancillary device and a stent that were easily treated without severe adverse consequences. ${ }^{49}$

The intentional improvement of stent radiopacity with the $\mathrm{PtCr}$ alloy used in Element ensures optimal stent visualization and parallely early detection of LSD. ${ }^{41}$ While the alloy composition on itself has been shown to provide superior tensile strength and density as compared with other alloys, the mechanical susceptibility to LSD with Element is primarily related to an offset peak-to-peak design and a limited $(n=2)$ number of connectors between different stent rings. ${ }^{17,45}$ This limitation has recently been addressed by inclusion of additional end connectors in the latest generation Rebel bare metal and in the everolimus-eluting Promus Premier and derived Synergy (Boston Scientific) stents, in order to optimize longitudinal robustness (Figure 3). A recent report confirmed an increased longitudinal strength of the Promus Premier stent in bench testing. ${ }^{50}$

Finally, awareness for the potential occurrence of LSD, irrespective of the stent platform used, should incite operators to implement a preventive behavior toward this entity. Indeed, optimal target lesion preparation and stent expansion, minimizing stent contact with guide catheter or guide catheter extension, and use of finesse rather than force when recrossing a freshly deployed stent, have been shown to minimize the risk of LSD. ${ }^{25}$

\section{Conclusion}

Thin-strut PtCr coronary stent platforms combine improved acute mechanical performance in terms of flexibility, deliverability, conformability, radial strength, and visibility, with favorable long-term clinical results in both BMS and DES versions. Recent alterations in stent design have successfully addressed concerns of longitudinal stent distortion by adding a limited number of stent segment connectors for increased proximal robustness. Improvements in stent design with $\mathrm{PtCr}$ stent series therefore illustrate the delicate balance between optimal stent concept and clinical failure. Growing evidence in a wide variety of clinical scenarios can truly position latest generation $\mathrm{PtCr}$ stent platforms for BMS and DES among best-in-class for contemporary PCI practice.

\section{Disclosure}

$\mathrm{CD}$ has received institutional grants from Abbott Vascular, Medtronic, Biosensors International, and Boston Scientific. $\mathrm{CD}$ is member of the Scientific Medical Advisory Board of Boston Scientific. The authors report no other conflicts of interest in this work.

\section{References}

1. The World Health Organization. The Top Ten Causes of Death Fact Sheet 2012. 2015. Available from:http:/www.who.int/mediacentre/factsheets/ fs310/en/. Accessed February 1, 2015.

2. Fuster V, Mearns BM. The CVD paradox: mortality vs prevalence. Nat Rev Cardiol. 2009;6(11):669.

3. Bauters C, Meurice T, Hamon M, McFadden E, Lablanche JM, Bertrand ME. Mechanisms and prevention of restenosis: from experimental models to clinical practice. Cardiovasc Res. 1996;31(6):835-846. 
4. Nabel EG, Braunwald E. A tale of coronary artery diease and myocardial infarction. N Engl J Med. 2012;366(1):54-63.

5. Tamburino C, Latib A, van Geuns RJ, et al. Contemporary practice and technical aspects in coronary intervention with bioresorbable scaffold a European perspective.pdf. EuroIntervention. 2015;10:1-16.

6. Alfonso F, Byrne RA, Rivero F, Kastrati A. Current treatment of in-stent restenosis. J Am Coll Cardiol. 2014;63(24):2659-2673.

7. Moliterno DJ. Healing achilles - sirolimus versus paclitaxel. $N$ Engl $J$ Med. 2005;353(7):724-727.

8. McFadden EP, Stabile E, Regar E, et al. Late thrombosis in drug-eluting coronary stents after discontinuation of antiplatelet therapy. Lancet. 2004;364(9444):1519-1521.

9. Tsimikas S. Drug-eluting stents and late adverse clinical outcomes lessons learned, lessons awaited. J Am Coll Cardiol. 2006;47(10):2112-2115.

10. Grewe PH, Deneke T, Machraoui A, Barmeyer J, Müller KM. Acute and chronic tissue response to coronary stent implantation: pathologic findings in human specimen. $J$ Am Coll Cardiol. 2000;35(1): 157-163.

11. Windecker S, Kolh P, Alfonso F, et al. 2014 ESC/EACTS guidelines on myocardial revascularization: the task force on myocardial revascularization of the European Society of Cardiology (ESC) and the European Association for Cardio-Thoracic Surgery (EACTS). Eur Heart J. 2014;35(37):2541-2619.

12. Morice MC, Urban P, Greene S, Schuler G, Chevalier B. Why are we still using coronary bare-metal stents? J Am Coll Cardiol. 2013; 61(10):1122-1123.

13. Amin AP, Spertus JA, Cohen DJ, et al. Use of drug-eluting stents as a function of predicted benefit: clinical and economic implications of current practice. Arch Intern Med. 2012;172(15):1145-1152.

14. Pfisterer M, Brunner-La Rocca HP, Rickenbacher P, et al; BASKET. Long-term benefit-risk balance of drug-eluting vs bare-metal stents in daily practice: does stent diameter matter? Three-year follow-up of BASKET. Eur Heart J. 2009;30(1):16-24.

15. Tu JV, Bowen J, Chiu M, et al. Effectiveness and safety of drug-eluting stents in Ontario. N Engl J Med. 2007;357(14):1393-1402.

16. Greenhalgh J, Hockenhull J, Rao N, Dundar Y, Dickson RC, Bagust A. Drug-eluting stents versus bare metal stents for angina or acute coronary syndromes. Cochrane Database Syst Rev. 2010;(5):CD004587.

17. Menown IB, Noad R, Garcia EJ, Meredith I. The platinum chromium element stent platform: from alloy, to design, to clinical practice. $A d v$ Ther. 2010;27(3):129-141.

18. O'Brien BJ, Stinson JS, Larsen SR, Eppihimer MJ, Carroll WM. A platinum-chromium steel for cardiovascular stents. Biomaterials. 2010;31(14):3755-3761.

19. Turco MA. The integrity ${ }^{\circledR}$ bare-metal stent made by continuous sinusoid technology. Expert Rev Med Devices. 2011;8(3):303-306.

20. Kastrati A, Mehilli J, Dirschinger J, et al. Intracoronary stenting and angiographic results: strut thickness effect on restenosis outcome (ISAR-STEREO) trial. Circulation. 2001;103(23):2816-2821.

21. Gotman I. Characteristics of metals used in implants. J Endourol. 1997;11(6):383-389.

22. Messer RL, Mickalonis J, Lewis JB, et al. Interactions between stainless steel, shear stress, and monocytes. J Biomed Mater Res A. 2008;87(1): 229-235.

23. Allocco DJ, Jacoski MV, Huibregtse B, Mickley T, Dawkins KD. Coronary stents platinum chromium stent series - the TAXUS ${ }^{\mathrm{TM}}$ Element $^{\mathrm{TM}}\left(\mathrm{ION}^{\mathrm{TM}}\right)$, PROMUS Element ${ }^{\mathrm{TM}}$ and OMEGA ${ }^{\mathrm{TM}}$ stents. Intervent Cardiol. 2011;6(2):134-141.

24. Kastrati A, Schömig A, Dirschinger J, et al. Increased risk of restenosis after placement of gold-coated stents: results of a randomized trial comparing gold-coated with uncoated steel stents in patients with coronary artery disease. Circulation. 2000;101(21):2478-2483.

25. Bennett J, Dubois C. A novel platinum chromium everolimus-eluting stent for the treatment of coronary artery disease. Biologics. 2013;7(1): 149-159.
26. Soucy NV, Feygin JM, Tunstall R, et al. Strut tissue coverage and endothelial cell coverage: a comparison between bare metal stent platforms and platinum chromium stents with and without everolimuseluting coating. EuroIntervention. 2010;6(5):630-637.

27. Wang JC, Carrié D, Masotti M, et al. Primary endpoint results of the OMEGA Study: one-year clinical outcomes after implantation of a novel platinum chromium bare metal stent. Cardiovasc Revasc Med. 2015;16(2):65-69.

28. Stone GW, Teirstein PS, Meredith IT, et al; PLATINUM Trial Investigators. A prospective, randomized evaluation of a novel everolimus-eluting coronary stent: the PLATINUM (a prospective, randomized, multicenter trial to assess an everolimus-eluting coronary stent system [PROMUS Element] for the treatment of up to Two de Novo Cor. J Am Coll Cardiol. 2011;57(16):1700-1708.

29. Park KW, Kang S-H, Kang H-J, et al. A randomized comparison of platinum chromium-based everolimus-eluting stents versus cobalt chromiumbased Zotarolimus-Eluting stents in all-comers receiving percutaneous coronary intervention: HOST-ASSURE (harmonizing optimal strategy for treatment of cor. J Am Coll Cardiol. 2014;63(25):2805-2816.

30. Sketch MH, Ball M, Rutherford B, Popma JJ, Russell C, Kereiakes DJ. Evaluation of the medtronic (Driver) cobalt-chromium alloy coronary stent system. Am J Cardiol. 2005;95(1):8-12.

31. Nef HM, Möllmann H, Weber M, et al. Cobalt-chrome MULTI-LINK VISION-stent implantation in diabetics and complex lesions: results from the DaVinci-registry. Clin Res Cardiol. 2009;98(11):731-737.

32. Fajadet J, Wijns W, Laarman GJ, et al. Long-term follow-up of the randomised controlled trial to evaluate the safety and efficacy of the zotarolimus-eluting driver coronary stent in de novo native coronary artery lesions: five year outcomes in the ENDEAVOR II study. EuroIntervention. 2010;6(5):562-567.

33. Ishihara $\mathrm{S}$, Mawad ME, Ogata $\mathrm{K}$, et al. Histopathologic findings in human cerebral aneurysms embolized with platinum coils: report of two cases and review of the literature. AJNR Am J Neuroradiol. 2002;23(6):970-974.

34. Eppihimer MJ, Sushkova N, Grimsby JL, et al. Impact of stent surface on thrombogenicity and vascular healing: a comparative analysis of metallic and polymeric surfaces. Circ Cardiovasc Interv. 2013;6(4): 370-377.

35. Virmani R, Farb A, Guagliumi G, Kolodgie FD. Drug-eluting stents: caution and concerns for long-term outcome. Coron Artery Dis. 2004;15(6):313-318.

36. Finn AV, Nakazawa G, Joner M, et al. Vascular responses to drug eluting stents: importance of delayed healing. Arterioscler Thromb Vasc Biol. 2007;27(7):1500-1510.

37. Smits PC, Hofma S, Togni M, et al. Abluminal biodegradable polymer biolimus-eluting stent versus durable polymer everolimus-eluting stent (COMPARE II): a randomised, controlled, non-inferiority trial. Lancet. 2013;381(9867):651-660.

38. Natsuaki M, Kozuma K, Morimoto T, et al; NEXT Investigators. Biodegradable polymer biolimus-eluting stent versus durable polymer everolimus-eluting stent: a randomized, controlled, noninferiority trial. J Am Coll Cardiol. 2013;62(3):181-190.

39. SCAAR. Swedish Coronary Angiography and Angioplasty Registry. 2015. Available from: http://www.ucr.uu.se/swedeheart/index.php/ forskning-scaar/in-english/stent-reports. Accessed April 1, 2015.

40. Tamburino C, Capodanno D, Erglis A, et al. One-year outcomes in unselected patients treated with a thin-strut, platinum-chromium, paclitaxel-eluting stent: primary endpoint results from the TAXUS element European post-approval surveillance study (TE-PROVE). EuroIntervention. 2015;10(11):1261-1266.

41. Williams PD, Mamas MA, Fraser DG. How serious an adverse event is longitudinal stent deformation? Incidence and severity. Expert Rev Med Devices. 2012;9(5):449-451.

42. Hanratty CG, Walsh SJ. Longitudinal compression: a "new" complication with modern coronary stent platforms - time to think beyond deliverability? EuroIntervention. 2011;7(7):872-877. 
43. Mamas MA, Williams PD. Longitudinal stent deformation: insights on mechanisms, treatments and outcomes from the Food and Drug Administration Manufacturer and User Facility Device Experience database. EuroIntervention. 2012;8(2):196-204.

44. Arnous S, Shakhshir N, Wiper A, et al. Incidence, and mechanisms of longitudinal stent deformation (LSD) associated with biomatrix, resolute, element and xience stents: angiographic and case-by-case review of 1,800 PCIs. Catheter Cardiovasc Interv. 2014.

45. Leibundgut G, Gick M, Toma A, et al. Longitudinal compression of the platinum-chromium everolimus-eluting stent during coronary implantation: predisposing mechanical properties, incidence, and predictors in a large patient cohort. Catheter Cardiovasc Interv. 2013;81(5):206-214.

46. Prabhu S, Schikorr T, Mahmoud T, Jacobs J, Potgieter A, Simonton C. Engineering assessment of the longitudinal compression behaviour of contemporary coronary stents. EuroIntervention. 2012;8(2):275-281.

47. Ormiston JA, Webber B, Webster MWI. Stent longitudinal integrity bench insights into a clinical problem. JACC Cardiovasc Interv. 2011; 4(12):1310-1317.
48. Kereiakes DJ, Popma JJ, Cannon LA, et al. Longitudinal stent deformation: quantitative coronary angiographic analysis from the PERSEUS and PLATINUM randomised controlled clinical trials. EuroIntervention. 2012;8(2):187-195.

49. Thomas MR, Birkemeyer R, Schwimmbeck P, et al. One-year outcomes in 1,010 unselected patients treated with the PROMUS element everolimus-eluting stent: the multicentre PROMUS element European Post-Approval Surveillance Study. EuroIntervention. 2015;10(11): 1267-1271.

50. Ormiston JA, Webber B, Ubod B, White J, Webster MWI. Stent longitudinal strength assessed using point compression: insights from a second-generation, clinically related bench test. Circ Cardiovasc Interv. 2013;7(1):62-69.
Medical Devices: Evidence and Research

\section{Publish your work in this journal}

Medical Devices: Evidence and Research is an international, peerreviewed, open access journal that focuses on the evidence, technology, research, and expert opinion supporting the use and application of medical devices in the diagnosis, treatment and management of clinical conditions and physiological processes. The identification of novel

\section{Dovepress}

devices and optimal use of existing devices which will lead to improved clinical outcomes and more effective patient management and safety is a key feature. The manuscript management system is completely online and includes a quick and fair peer-review system. Visit http://www. dovepress.com/testimonials.php to read real quotes from authors.

Submit your manuscript here: http://www.dovepress.com/medical-devices-evidence-and-research-journal 